Fausto Viana é figurinista, cenógrafo

e pesquisador. Professor livre-

docente da ECA-USP. Coordenou o

projeto de catalogação do acervo

de figurinos do Theatro Municipal de São Paulo. Participa do projeto

de pesquisa As Tramas do Café com Leite. Colabora com o blog

www.vestindoacena.com.

E-mail: faustoviana@uol.com.br

Rosane Muniz é jornalista, atriz e autora do livro Vestindo os nus - o figurino em cena (Senac Rio, 2004). Especializada em Jornalismo Cultural (PUC-SP), é mestranda em Artes Cênicas (ECA-USP) com a pesquisa A trajetória de Gianni Ratto na indumentária. Mantém o blog www.vestindoacena.com.

E-mail: romuniz@gmail.com

\title{
Muito além de teatro e moda
}

É para pensar a criação de uma indumentária cênica que se pesquisa sobre figurino.

Problema 1 - 0 que é indumentária cênica? Muito mais simples e ao mesmo tempo mais complexo do que se pode imaginar nestes tempos pós-modernos. Simples, na medida em que se trata da roupa de cena. Complexo, quando se pensa no que significa cena. Vá lá: área de atuação de atores.

Problema 2 - Definir área de atuação. Falamos do espaço cênico ou falamos das diversas especialidades às quais um ator pode se dedicar? Os dois. Espaço cênico é um local onde acontece uma cena, não necessariamente um teatro de palco convencional, como o Municipal de São Paulo. 0 Presídio do Hipódromo foi usado como área de encenação no espetáculo do Teatro da Vertigem! As cenas aconteciam por todo o presídio. 0 mesmo grupo já ocupou hospitais abandonados e igre-

[29]

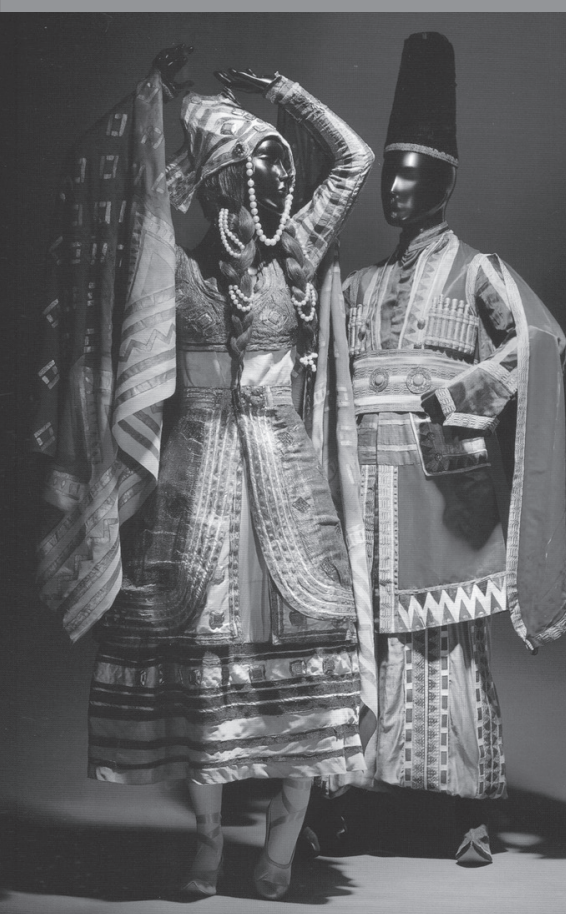

Figurinos de

Léon Bakst para

os Balés Russos,

de Diaghilev,

expostos na

National Gallery

of Austrália

(1998). 
$[30]$

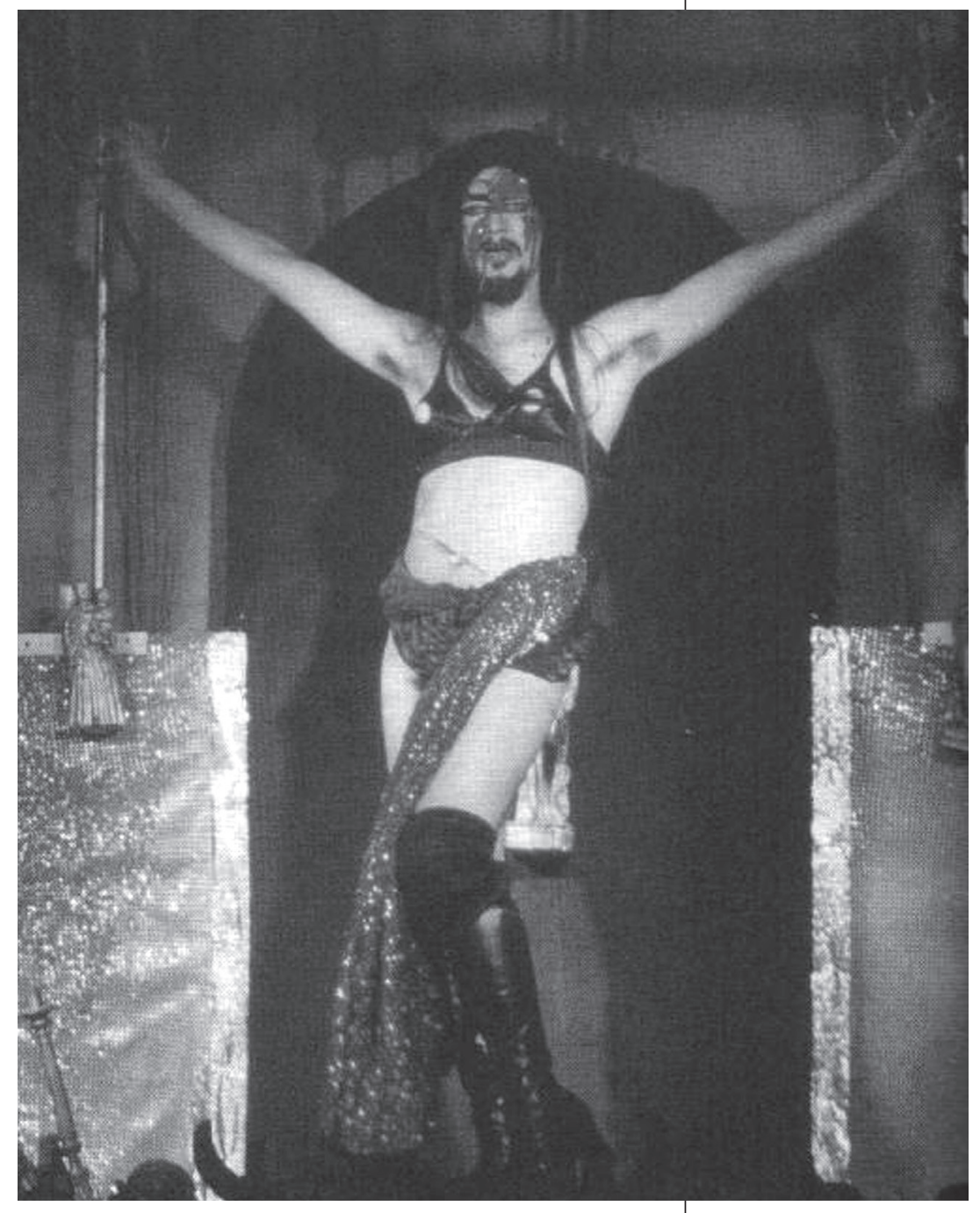

jas. Há pouco tempo, havia um espetáculo no banheiro de um shopping na Rua Maria Antônia. 0 Grupo XIX de Teatro tem sua sede em um galpão de boticário da década de 1930 na Vila Operária Maria Zélia. Há espetáculos no meio da rua. Em circos... cabarés... boates de primeira... - oras, como se há de esquecer os shows para turistas? - e de quinta "catiguria". E por falar neste bordão televisivo atual, há as cenas gravadas para televisão... cinema... e os comerciais que passam nas duas, ou isoladamente em cada uma das mídias, sem esquecer da eletrônica - especificamente, a internet. Ou o seu YouTube mostra as pessoas sem trajes? Neste caso, é o XTube. Mas, até lá as pessoas estão com algum traje, confira. Nudez também é figurino dentro da proposta de alguns atores. E aí vem a grande dificuldade...

Problema 3 - Definir quem é ator! Questão das mais dificeis, aparentemente. Mas, eliminando uma boa dose de preconceito, o "ator" é aquele que atua no projeto em que estamos trabalhando, que tem a

Figurino de Fábio Namatame para

"Apocalipse 1.11", do Grupo Vertigem, no Presídio do

Hipódromo (2000). 
finalidade de dizer algo a alguém. Assim, trabalhamos para trajar, ou "vestir a alma do ator", como citou o jornalista Carlos Haag. Este pode ser o Paulo Autran, um aluno de escola de teatro ou a Samanta Boca de Veludo, do filme pornô mais recente. Sim, o Gianecchini também é.

A partir destas breves e lúdicas definições, pergunta-se: Como se reflete sobre a criação de determinado artista para um espetáculo?

Os croquis são uma fonte inegável de informação, claro. Mas quem garante que, em primeiro lugar, os trajes foram executados da forma pensada? 0 que se passou entre a concepção e a execução? A investigação vai levar ao entendimento de como aquela peça subiu ao palco. Seu significado só passa a ter sentido quando analisamos como ela foi usada em cena. A história daquela peça nunca mais será a mesma depois de colocada no corpo de um ator...

0 que faz da própria peça uma fonte de pesquisa. E por isso se justifica e se busca tanto preservar os trajes históricos. Entendê-los é compreender a arte, o pensamento criativo e a força de expressão de determinado período. Um traje na reserva técnica, porém, além de ser tarefa que exige vários profissionais, exige manutenção. Que tem custos. 0 que faz da fotografia uma outra possibilidade de documentação viável.

A foto mostraria, por exemplo, as diversas fases de um figurino. Por que a peça, hoje, tem centenas de flores se na foto do espetáculo Cosi fan Tutti (Theatro Municipal de São Paulo, 1971) não tinha nada disso?

Ah, sim, faltou dizer que o teatro - e não há como negar certa preferência pessoal pela execução dos figurinos desta área - é um precursor na conservação ecológica do planeta! Reduzir a perda, reutilizar e reciclar são palavras-chave da indumentária e da cenografia. Os figurinos, muitas vezes, seguem este caminho antes do descarte - 0 que nos leva a descobrir que as flores de Cosi fan Tutti foram colocadas para uma peça com Marisa Orth, na década de 1980. São os caminhos da pesquisa...

Entra aí outra discussão: se o acervo é museológico, como Cosi fan Tutti, do maior teatro de ópera ao longo da História do Brasil, o que preservamos? Reconstruímos o Cosi de 1971, do renomado cenógrafo Campello Neto ou mantemos o "novo" Cosi dos anos 1980, de Orth? Marisa não mudou a história do figurino? Mudou. Se um ator tivesse morrido com este traje, tanto melhor - para o traje. Seria sua glória eterna! Daí segue que os figurinos precisam de uma política de preservação, conservação e descarte. Nela, pode estar prevista a reconstrução - ou não.

Reconstruir atinge dimensões inimagináveis. A National Gallery of Australia exibiu, em 1998, uma coleção de trajes dos Balés Russos de Diaghilev. 0 período coberto pela exposição foi 1909-1933. Os artistas que haviam concebido os trabalhos? Pablo Picasso, Alexander Benois, Natalia Gontcharova, Léon Bakst, Aleksandr Golovin, Henri Matisse...

No nosso caso, fomos até Moscou para descobrir como o mesmo Golovin citado acima, antigo cenógrafo dos Teatros Imperiais Russos, trabalhava no Teatro de Arte de Moscou, de um dos grandes pesquisadores da interpretação do século XX, Konstantin Stanislavski. Na reconstrução, mostrada no Salão dos Arcos do Theatro Municipal em 2004, chegamos ao entendimento de como a fome, a miséria e até mesmo a morte estiveram presentes na criação dos magníficos trajes de Bodas de Fígaro, em 1928, na capital russa.

Como se vê, a pesquisa sobre figurino que propomos discutir neste espaço envolve uma série de fatores que fazem dela uma grande aventura. Mas claro que vamos pensar como fica o caso de O Diabo Veste Prada. Meryl Streep usa moda ou figurino? A resposta certamente nos remete ao título da nossa coluna. 